\title{
UMA ANÁLISE DA NOVA POLÍTICA DE COMPRAS DA PETROBRAS PARA SEUS EMPREENDIMENTOS OFFSHORE
}

\section{AN ANALYSIS OF THE NEW PETROBRAS'S PROCUREMENT POLICY FOR ITS OFFSHORE ENTERPRISES}

\author{
Cássio G. Ribeiro Soares da Silva ${ }^{1}$, André Tosi Furtado ${ }^{2}$ \\ ${ }^{1}$ State University of Campinas - Unicamp - Campinas - Brasil - cassio@ige.unicamp.br \\ ${ }^{2}$ State University of Campinas - Unicamp - Campinas - Brasil - furtado@ige.unicamp.br
}

\begin{abstract}
Resumo
Este artigo trata da política de compras da Petrobras para seus empreendimentos offshore no período recente, mais especificamente a partir do governo Lula, e está vinculado à dissertação de mestrado do autor. O governo atual criou alguns mecanismos para estimular a reaproximação da Petrobras com a indústria para-petroleira local, a qual no decorrer de quase uma década de vigência do modelo neoliberal, viu-se órfã do modelo de aquisição local de grande maioria dos materiais e equipamentos necessários à atividade da operadora nacional, ou seja, do modelo substitutivo de importações. A criação do PROMINP é um exemplo claro do objetivo do governo em modificar essa situação. Nosso objetivo neste trabalho é analisar até que ponto a nova politica de compras da Petrobras para suas atividades de exploração e produção consegue se desvencilhar do tradicional modelo de substituição de importações, de modo a fomentar a capacitação e aprendizagem tecnológica dos fornecedores locais. Para tanto é feita num segundo item uma revisão bibliográfica apoiada na literatura existente acerca do panorama histórico da política de compras da Petrobras, destacando a questão tecnológica em suas compras. Num terceiro item apresenta-se a análise do PROMINP. Tal análise se apóia em documentos e entrevistas realizadas junto a participantes deste Programa. Finalmente, no quarto item, busca-se analisar, a partir dos elementos apresentados nos dois itens anteriores, se o atual modelo de compras da Petrobras efetivamente cria uma nova oportunidade de aprendizagem e capacitação tecnológica à indústria para-petroleira local.
\end{abstract}

Palavras-chave: política de compras, aprendizagem tecnológica, indústria para-petroleira, PROMINP.

\section{Introdução}

O objetivo deste artigo é examinar a política de compras realizada pela Petrobras ao longo de sua história, enfatizando a questão tecnológica nas aquisições da estatal nacional. Ao período recente é dado especial destaque.

Inicialmente é apresentada uma caracterização da indústria em questão, assim como, um histórico da política de compras da Petrobras. As mudanças pelas quais passaram a indústria de 
Petróleo e Gás Natural (P\&GN) no Brasil a partir dos anos 1990, são apresentadas neste artigo. Nesse período o governo brasileiro introduz importantes mudanças, primeiramente no plano macroeconômico, como a abertura da economia e a sobrevalorização do câmbio e, em seguida, as reformas no plano institucional, destacando-se aqui a quebra do monopólio da Petrobras, a criação da ANP (Agência Nacional de Petróleo) e do CNPE (Conselho Nacional de Política Energética) no ano de 1997 e a instauração de um novo regime tributário para a indústria de P\&GN (o REPETRO) que repercutem significativamente sobre a política de compras da Petrobras.

As mudanças organizacionais implementadas pela Petrobras ao longo da década passada e os desdobramentos de tais mudanças sobre a relação Petrobras - fornecedores locais, também são abordados, assim como, a revisão recente desse modelo organizacional. Vale lembrar que a análise da política de compras da Petrobras contempla, sobretudo, as atividades a montante da cadeia (upstream), em especial aquelas levadas a cabo em bacias marítimas, em virtude da importância deste segmento dentro das atividades da Petrobras nos últimos tempos ${ }^{1}$.

O Programa de Mobilização da Indústria Nacional de Petróleo (PROMINP), mecanismo lançado pelo governo brasileiro com o objetivo de fazer da produção de petróleo e gás natural, transporte marítimo e dutoviário, oportunidades de crescimento para a indústria para-petroleira ${ }^{2}$ local é objeto de estudo neste artigo. Objetiva-se através de tal estudo analisar se o PROMINP, Programa que representa a agenda explícita do governo atual para a indústria de P\&GN, tem impelido a Petrobras a adotar uma estratégia de compras que fomente a capacitação e o aprendizado tecnológico dos fornecedores locais, ou seja, se através do PROMINP o governo brasileiro tem criado um ambiente propício à inovatividade da indústria para-petroleira local.

\section{A Indústria de Petróleo e Gás Natural: Caracterização e Histórico no Brasil}

A indústria do petróleo e gás natural apresenta um sistema setorial de inovação composto por um conjunto de atores heterogêneos (empresas, instituições de pesquisa e governo) articulados entre si. Tal sistema, pelo lado produtivo, conta com dois tipos de empresas, a saber: as operadoras e os fornecedores. As operadoras assumem as diversas etapas da cadeia produtiva do petróleo e do gás natural, que vai da exploração e produção (E\&P) de petróleo até a distribuição do produto final processado. Já o grupo dos fornecedores se caracteriza pela heterogeneidade de suas empresas, as quais suprem as operadoras de uma vasta gama de bens, materiais e equipamentos complexos, além

\footnotetext{
${ }^{1}$ O segmento offshore é aquele que mais têm crescido na Petrobras nos últimos anos. Além disso, a maior parte da produção nacional de petróleo é extraída de campos marítimos. Em 2002, a produção de petróleo em campos marítmos respondeu por 83,4\% da produção nacional (ANP, 2002).

${ }_{2}^{2} \mathrm{O}$ conceito indústria "para-petroleira" tem origem na literatura francesa e engloba todos os segmentos fornecedores de equipamentos, tecnologia e serviços especializados, necessários à indústria de petróleo e gás (Zamith, 1999).
} 
de prestarem uma grande diversidade de serviços de apoio à produção do primeiro grupo de empresa (Furtado, 2004).

A relação usuário-fornecedor possui uma importância central para a dinâmica econômica e tecnológica da indústria de P\&GN. A relação de forças entre grandes companhias operadoras e os fornecedores bastante especializados sempre se inclinou do lado das primeiras no que diz respeito ao volume do esforço tecnológico, sobretudo no campo de tecnologias offshore ${ }^{3}$.

Normalmente, uma grande companhia de petróleo dispõe de um grande poder de barganha frente aos seus sub-contratados e fornecedores. Contudo, em algumas atividades as empresas fornecedoras conseguiram melhorar as condições de negociação, a partir do monopólio de determinadas inovações tecnológicas. A segmentação das atividades complexas em um conjunto heterogêneo de tecnologias acabou gerando um grande número de nichos de mercado. As atividades e processos de fabricação que demandavam vultosos investimentos em P \& D, ou um aprendizado técnico marcadamente tácito, deram origem a mercados nos quais os fornecedores passaram a contar com condições mais favoráveis para negociar os contratos com as operadoras (Furtado et alli, 2003).

Nas contas nacionais as operadoras e seus fornecedores são classificados separadamente. Contudo, no presente artigo utiliza-se o termo indústria de P\&GN abarcando não apenas as operadoras como também seus fornecedores, em virtude da proximidade dessas duas indústrias.

O segmento petroleiro foi um dos pilares do modelo de Industrialização por Substituição de Importações $^{4}$ (ISI) adotado pelo Brasil a partir da segunda metade do século passado. A Petrobras foi criada em 1953, visando diminuir as restrições à industrialização, relativas a uma base pobre de recursos petrolíferos. A estatal brasileira que atua nas três etapas da indústria de P\&GN (E\&P) é o principal ator desta indústria no Brasil. No decorrer das três primeiras décadas de sua existência (1953-1983), as diretrizes políticas do Estado brasileiro centradas no desenvolvimento da indústria doméstica, mediante a adoção de uma política de substituição de importações, foram encampadas pela Petrobras (Macedo e Silva, 1983). A Petrobras serviu de instrumento para a consolidação da indústria de bens de capital sob encomenda do Brasil.

Em seus primeiros anos de vida (sobretudo entre as décadas de 1950 e 1980), a operadora nacional adotou uma política de estímulo ao desenvolvimento da indústria de bens de capital no Brasil, com vistas a tornar tal indústria apta a participar dos seus projetos de construção de

\footnotetext{
${ }^{3}$ Exploração e Produção de petróleo e gás natural em bacias marítimas, fora do continente.

${ }^{4}$ A Industrialização por Substituição de Importações (ISI) é um processo interno, que tem lugar e se orienta sob o impulso de restrições externas, gerando ampliação e diversificação da capacidade produtiva industrial (Tavares, 1973).

${ }^{5}$ Primeira Etapa - Upstream, ou "etapas a montante": etapa na qual ocorrem a Exploração, o Desenvolvimento e a Produção de petróleo e gás natural; Segunda Etapa - Midstream, ou "etapas intermediárias": nesta etapa se dá o Transporte, ou seja, a movimentação de petróleo e seus derivados, ou gás natural, em meio ou percurso de interesse geral; e Terceira Etapa - Dowstream, ou "etapas a jusante": na etapa em questão ocorrem o Refino de Petróleo, o Processamento de gás natural e a Distribuição, ou seja, a comercialização por atacado com a rede varejista, ou com grandes consumidores de combustível, lubrificantes, asfalto e gás liquefeito envasado, exercida por empresas especializadas, nas formas das leis e regulamentos aplicáveis (Martins, 2003).
} 
refinarias e infra-estrutura de produção, transporte e distribuição de petróleo e derivados. Essa política implementada pela Petrobras apresentou três frentes de atuação: 1) estímulo à transferência de tecnologia, inclusive mediante a participação de firmas brasileiras em projetos conjuntos com firmas estrangeiras; 2) estimulo à criação de uma associação dos fabricantes de equipamentos (ABDIB), cuja principal tarefa seria difundir normas e procedimentos de controle de qualidade e; 3) criação de um sistema de pré-qualificação de fornecedores em seu Serviço de Materiais (Semart) que, além de verificar a capacidade financeira e gerencial, fornecia a orientação e a assistência técnica necessária ao desenvolvimento da capacitação tecnológica dos fornecedores, cuja mola mestra era o controle de qualidade (Alonso, 2004, pp. 22 e 23).

Na década de 1970 e o início da década de 1980 os Planos Nacionais de Desenvolvimento (PNDs) alavancaram os investimentos na indústria nacional, repercutindo positivamente sobre a indústria de petróleo e gás natural. Os PNDs, editados pelos governos militares, tinham como foco a substituição de importações. Os Planos abarcavam um período de cinco anos e determinavam que era absolutamente proibido importar tudo que pudesse ser fabricado no Brasil ou que tivesse similar nacional. Criaram-se barreiras de toda ordem para barrar o processo de importação, evidenciando a intenção do governo brasileiro em promover a substituição de importações na indústria local (Souza, 1997).

No período analisado, a operadora nacional, pelo seu poder de referência junto ao mercado já havia criado um sistema de normas técnicas e métodos de controle de qualidade independente da Associação Brasileira das Indústrias de Base (ABDIB) o que lhe permitiu desenvolver critérios próprios de escolha de seus fornecedores. O credenciamento da Petrobras, além de ter servido como barreira à entrada de fornecedores estrangeiros, revela também uma preocupação estratégica, segundo Alonso (2004, p. 24):

“O programa de investimentos da Petrobras, base de todo seu processo de crescimento, não poderia ser afetado pelas crises cambiais que, já na época, assolavam o país. A garantia de um fornecimento interno, além de evitar a queima de divisas, não vinculava o projeto à necessidade de financiamento externo".

Logo, destaca-se que a nacionalização das compras da Petrobras no período estudado, não decorreu apenas do nacional-desenvolvimentismo da estatal. A questão cambial e a restrição de divisas, como já mencionado, também impeliram a Petrobras a adensar seu relacionamento com a indústria para-petroleira local, tornando-a preocupada com o desenvolvimento produtivo e tecnológico dessa.

É importante destacar que, entre a década de 1950 e início da década de 1970, as atividades da Petrobras se concentravam a jusante da cadeia da indústria de P\&GN. Nesse período, a operadora nacional buscou ampliar suas compras de materiais e equipamentos no parque supridor 
local. Tais materiais e equipamentos foram utilizados na ampliação das refinarias existentes e na construção de novas.

A primeira fase da política de compras da Petrobras para seu segmento offshore, que vai da década de 1970, quando a Petrobras inicia a exploração e produção de petróleo e gás natural em reservas marítimas, até a primeira metade da década de 1990, é fortemente marcada pelo modelo de desenvolvimento seguido pelo governo brasileiro, qual seja, o modelo Industrialização por Substituição de Importações (ISI). A compra de similares nacionais balizou os investimentos em E\&P da estatal brasileira no período em questão.

Para alcançar as metas de auto-suficiência e contar com equipamentos modernos, a Petrobras desenvolveu na década de 1970 o Programa de "Produtos Pioneiros", o qual se caracterizava pela encomenda à fornecedores locais, a preços acima dos praticados pelos fornecedores estrangeiros, com o objetivo de subsidiar a atividade tecnológica da empresa fornecedora nacional. Mediante a introdução deste Programa a Petrobras buscava alcançar três objetivos básicos: 1) substituir importações; 2) incentivar o desenvolvimento dos fornecedores nacionais e; 3) estimular o desenvolvimento de tecnologias endogenamente (Alonso, 2004, p. 25). Para que tais objetivos fossem alcançados, a operadora nacional organizou, uma estrutura sistemática, engajando diversos órgãos e departamentos da companhia, que deveriam trabalhar em sincronia. Segundo Alonso:

\footnotetext{
“As exigências e requisitos de qualificação eram rígidas e avaliadas sistematicamente pelos engenheiros do Serviço de Material da companhia. O sistema de avaliação colocava esses engenheiros no chão da fábrica do fornecedor, atuando diretamente nos processos produtivos e opinando em todas as etapas, desde aceitação de matéria-prima até embalagem. Como resultado de todas essas ações, o índice de nacionalização em preço de plataformas já atingia cerca de 90\% em 1983” (Alonso, 2004, p. 26).
}

Assim, fica evidente que a Petrobras, a partir de sua posição de monopsônio na compra de equipamentos adotou, no período analisado, mecanismos de capacitação dos fornecedores locais de equipamentos, que abarcavam o domínio tecnológico da produção de tecnologias complexas e a absorção de tecnologias geradas no $\mathrm{CENPES}^{6}$, o centro de pesquisa da Petrobras. Tais políticas se intensificaram entre as décadas de 1970-80, a partir das duas crises do petróleo (1973 e 1979) e do endividamento externo, uma vez que serviam para minorar a vulnerabilidade externa da economia brasileira (Furtado, 2002; ANP, 1999).

\footnotetext{
${ }^{6}$ O CENPES - "Centro de Pesquisa e Desenvolvimento Leopoldo Américo Miguez de Mello" - foi criado em 1966, inicialmente centrando esforços nos segmentos a jusante da cadeia de valor da indústria de petróleo e gás natural (Refino e Petroquímica). Após os choques dos anos 1970, quando 90\% das atividades da Petrobras passam a se concentrar na etapa a montante da cadeia, o centro se reestrutura, suas atividades passam a se concentrar na descoberta e delimitação de novas reservas petrolíferas, principalmente em bacias marítimas (Martins, 2003).
} 
Mediante um esforço tecnológico pioneiro, a estatal brasileira foi capaz de prover o país de importantes reservas petrolíferas, diminuindo o impacto dos choques do petróleo. A descoberta do campo de Garoupa, na bacia de Campos, em 1974, à lâmina d'água (LDA) de 120 metros de profundidade, representou um marco histórico para o setor petrolífero nacional. Em seguida foram descobertos os campos de Badejo, Namorado, Cherne, Enchova, dentre outros.

Em meados da década de 1980, quando o Brasil ainda importava praticamente metade do petróleo consumido, a Petrobras descobre grandes reservatórios localizados em águas profundas (mais de 400 LDA), deixando-a mais próxima de alcançar a meta da auto-suficiência. A partir daí, o grande desafio colocado à operadora nacional foi viabilizar a produção de petróleo em águas profundas, em virtude da "geologia rebelde" das formações sedimentares brasileiras (Furtado e Freitas, 2004).

A exploração e produção em bacias marítimas demandaram, de início, que fossem realizadas encomendas de equipamentos, materiais e serviços de empresas situadas no exterior, uma vez que a Petrobras e o parque supridor nacional não tinham know-how para a construção de plataformas e sistemas de produção marítimos. Este fator fez oscilar para baixo o índice de compras da Petrobras dentro do país, para o patamar de 52\% em 1980 (Furtado e Freitas, 2004).

Nesse período, a Petrobras inicia um significativo processo de inovação tecnológica para desenvolvimento e exploração de petróleo em águas profundas e ultra-profundas, destacando-se as pesquisas que ela passa a desenvolver in house, no CENPES, para viabilizar a extração de petróleo sob estas condições. Na primeira metade da década de 1980, a operadora nacional logra consolidar seu aprendizado mediante o desempacotamento da tecnologia, o que a torna apta para a fase seguinte, de inovação tecnológica (Martins, 2003). As inovações desenvolvidas pela Petrobras para E\&P de petróleo e gás natural em bacias marítimas foram rapidamente absorvidas pelos fornecedores locais e já no ano de 1983 as compras da Petrobras aqui no país estavam na casa dos $80 \%$. Deve-se destacar que grande parte das empresas fornecedoras estabelecidas fora do país, sobretudo a partir desta nova fase da política de compras da Petrobras, buscou estabelecer parcerias com empresas brasileiras, ou abriu filiais aqui no país (ANP, 1999).

Através da nova trajetória que passa a seguir, a Petrobras conseguiu ampliar a capacidade de fornecimento local de petróleo ${ }^{7}$, entretanto, deu pouca atenção à capacitação tecnológica para inovar dos fornecedores locais, uma vez que, estes na maior parte das vezes, eram chamados a demonstrar que possuíam capacitação tecnológica para replicar tecnologias desenvolvidas pela Petrobras ou por

\footnotetext{
${ }^{7}$ Em 1982, a Petrobras já produzia mais de 100 mil barris por dia em seus campos offshore. Esta produção elevou-se para 1.300 mil barris dia em 2002, sendo 900 mil barris/dia em águas profundas (lâmina d'água acima de 400 metros). Desta forma, o esforço tecnológico empreendido pela Petrobras resultou na redução da dependência do Brasil em relação à importação do petróleo. Em 1997, a Petrobras já atendia cerca de $70 \%$ da demanda nacional de petróleo com produção própria. Atualmente, a dependência externa situa-se em torno de $15 \%$ (Almeida, 2003).
} 
empresas estrangeiras. Eram raros os casos em que a Petrobras encomendava de um fornecedor local o desenvolvimento de um produto ou sistema que não estivesse na "prateleira”.

\subsection{As Reformas Neoliberais e a Indústria de Petróleo e Gás Natural}

A emergência de um novo consenso mundial nos anos 1990 resultou na revisão das políticas para o setor de energia no Brasil. Especificamente no caso da indústria de P\&GN, o governo brasileiro promoveu mudanças no plano institucional cujo objetivo foi criar um novo ciclo de investimentos nessa indústria, através da entrada de novos players internacionais. Além disso, no plano macroeconômico, a sobrevalorização do real também teve importantes reflexos sobre a dinâmica da indústria em questão (Almeida, 2003).

Uma das reformas implementadas pelo governo brasileiro na década de 1990 é a constituição de um novo arcabouço institucional para a indústria de P\&GN. Tal arcabouço foi inaugurado com a nova lei de concessões de serviços públicos (Lei n. 8987/95), que estabeleceu a base jurídica para a concorrência e para a atuação da iniciativa privada em projetos energéticos. Essa lei submeteu todos os serviços públicos a licitações públicas prévias, introduzindo assim a competição nos investimentos para a expansão do setor. A quebra do monopólio legal da Petrobras se deu em 1997, com a aprovação da Lei n. 9.478, que autorizou o Governo federal a contratar empresas públicas ou privadas para participar das atividades econômicas antes reservadas a operadora brasileira, quais sejam: exploração, produção, refino, exportação, importação e transporte de bens e derivados de petróleo (Bonneli e Veiga, 2003).

A partir da aprovação da Lei do Petróleo (como ficou conhecida a Lei No. 9478/97), criouse o Conselho Nacional de Política Energética $\left(\mathrm{CNPE}^{8}\right)$ e a Agência Nacional de Petróleo (ANP ${ }^{9}$, os quais passaram a ocupar os vértices da política pública e da regulação, respectivamente. A Petrobras se centrou na operação, mas a partir da Lei do Petróleo, a operadora nacional perde a posição de monopólio que ocupava até então.

A respeito da constituição do novo arcabouço jurídico para a indústria de petróleo e gás natural, também é importante destacar a implementação de um novo regime tributário para tal indústria no ano de 1999, denominado Repetro (Regime Aduaneiro Especial para a Indústria do Petróleo), o qual

\footnotetext{
${ }^{8}$ O CNPE tem por atribuição assessorar a Presidência da República na formulação de políticas e diretrizes para o setor energético brasileiro.

9 A Agência Nacional do Petróleo é uma autarquia vinculada ao Ministério de Minas e Energia (MME), criada a partir da promulgação da Lei do Petróleo. Sua função é zelar pelo adequado funcionamento da indústria de petróleo e gás natural em bases competitivas.
} 
franqueou de qualquer tributação a importação de equipamentos destinados à exploração e produção offshore ${ }^{10}$.

O novo regime tributário desfavoreceu a indústria para-petroleira local, pois mesmo com a criação do sistema de "exportação ficta" pelo Governo Federal, com o objetivo de compensar os fornecedores locais da concorrência desigual dos produtos importados, a produção local ficou desonerada dos impostos federais, mas não se livrou dos impostos estaduais (Furtado, 2002).

No que toca ao plano macroeconômico, nos anos 1990 ocorre a abertura da economia brasileira ao mercado externo e a sobrevalorização do câmbio. Num contexto de abertura da economia às tecnologias e ao comércio estrangeiro e de câmbio sobrevalorizado, houve um estímulo para que se importasse tecnologia incorporada e desincorporada e, em conseqüência disso, percebeu-se um recuo nas encomendas feitas pela Petrobras aos fornecedores locais (Furtado, 2002; Martins, 2003).

Resumindo, a partir da década passada com as mudanças que se observa, primeiramente no plano macroeconômico, como a abertura da economia e a sobrevalorização do câmbio e, em seguida, com as reformas no plano institucional, destacando-se aqui a quebra do monopólio da Petrobras, a criação da ANP e do CNPE e a instauração de um novo regime tributário para a indústria de petróleo e gás natural (o REPETRO), observa-se um certo abalo nos elos que existiam entre a Petrobras e a indústria para-petroleira local, em que a estatal brasileira diminui o índice de nacionalização de suas compras.

Outro aspecto que concorreu para a diminuição das encomendas da estatal brasileira aos fornecedores locais de bens e serviços para o segmento offshore diz respeito às mudanças organizacionais que a Petrobras passa a implementar a partir dos anos 1990, como é abordado a seguir.

\subsubsection{O Novo Modelo Organizacional da Petrobras}

Seguindo as tendências internacionais a Petrobras, a partir da década de 1990, passa a externalizar boa parte das funções que costumava assumir em seus grandes projetos de investimento. Segundo Furtado et alli (2003), "a Petrobras busca externalizar parte importante dos custos de transação que ela tinha que assumir no desenvolvimento dos novos campos offshore descobertos na Bacia de Campos" (Furtado et alli, 2003, p. 10).

O controle e a integração dos empreendimentos, bem como a parte financeira do projeto, estão entre essas funções externalizadas pela operadora nacional. Em decorrência das mudanças que

\footnotetext{
${ }^{10}$ Segundo Furtado (2002) nesse novo regime tributário, “Os equipamentos permanecem por um tempo determinado em solo nacional (durante o contrato de concessão) sem ter que pagar impostos federais (Imposto de Importação, PIS Cofins e IPI) e estaduais (ICMS)" (Furtado, 2002, p. 4).
} 
ocorreram desde o início da década passada, a companhia passou a se relacionar com contratantes principais (chamados de main contractors), os quais se integraram aos projetos "Turn-Key" 11 . O formato de contrato que a Petrobras passou a buscar foi o do Engineering, Procurement and Construction (EPC), no qual, um contratante principal, a serviço da companhia de petróleo, centraliza as atividades e subcontrata outras firmas fornecedoras de equipamentos e serviços (Martins, 2003).

A consagração de contratos do tipo EPC entre companhias petrolíferas e contratantes principais estabelece que a empresa de engenharia fica a cargo da execução do conjunto do projeto. Esta empresa, além de executar as diferentes partes do projeto de forma coordenada, deve ser capaz de integrá-las eficazmente. Outra característica importante desse modelo contratual é o fato de que a função de negociar os preços e de controlar a qualidade dos diferentes equipamentos que integram o projeto, fica a cargo da contratante principal (Martins, 2003; Furtado et alli, 2003).

Essas mudanças organizacionais estão no cerne da transição ocorrida na relação da Petrobras com a indústria para-petroleira local. A Petrobras, a partir desse período, passou a demandar mais destes fornecedores (no que toca ao preço, produção e qualidade), num momento em que a indústria de bens de capital e bens intermediários encontrava-se enfraquecida. O aumento do grau de exigência da Petrobras em relação aos seus fornecedores aqui instalados, concomitante ao enfraquecimento destes, ajuda a explicar porque houve redução das compras locais da operadora brasileira nesse período.

A troca que a Petrobras realiza em seus parceiros principais - na qual os parceiros nacionais dão lugar aos estrangeiros - fica evidente a partir do seguinte dado: no ano de 1999, das 12 unidades de produção encomendadas pela Petrobras, somente uma estava sendo construída no país, qual seja, a P-31 (Brasil Energia, Maio de 1999). Observa-se, ao se analisar a aquisições recentes da Petrobras, uma revisão acerca desse modelo organizacional. Tal revisão é analisada no próximo item.

\subsubsection{A Revisão do Modelo “Turn-Key"}

A partir do final da década passada e do inicio da atual, a Petrobras passou a rever sua estratégia de externalização de custos e atividades, em decorrência de problemas que passou a enfrentar no que diz respeito à qualidade dos produtos e tempo de entrega dos fornecedores. Furtado et alli (2003) argumentam que a postura da Petrobras está mudando mais recentemente, especialmente no que tange ao seu relacionamento com as empresas de engenharia, o que tem interferido em sua estratégia de compras. Em decorrência dos atrasos e dificuldades observadas na

\footnotetext{
${ }^{11}$ Chave-na-mão. Termo em inglês; faz parte do jargão da indústria (Zamith, 1999).
} 
entrega dos projetos “Turn-Key" por parte dos contratantes principais, a Petrobras tem procurado readquirir um maior controle sobre a parte de engenharia.

A tendência em curso tem sido o acompanhamento por parte do Departamento de Engenharia da Petrobras do detalhamento dos projetos e do comissionamento, que consiste em colocar os equipamentos em condição de funcionar. A operadora brasileira, nessa nova modalidade de relacionamento com seus parceiros, passa a ser responsável pelos testes dos instrumentos, acionamento das bombas, integração dos grandes equipamentos e teste do conjunto do sistema. A nova modalidade de relacionamento está levando-a a abandonar os projetos "Turn-Key" para contratar módulos que depois ela se encarrega de integrar (Furtado et alli, 2003, p. 14).

Além do abandono dos projetos "Turn-Key", as licitações das plataformas P-51 e P-52 reforçam a idéia de que há uma intenção por parte da Petrobras de voltar a nacionalizar suas compras, tendo em vista que, em tais licitações se segmentou os projetos em vários módulos (geração, compressão, casco/topside) e estipulou-se um conteúdo local cada vez mais elevado. A exigência quanto ao grau de nacionalização do módulo de geração e compressão é de $75 \%$, sem contar os grandes equipamentos como compressores e turbogeradores. No que diz respeito aos serviços de engenharia, construção e montagem, ficou estabelecido que eles terão que ser feitos integralmente no Brasil. O topside deve conter $60 \%$ de índice de nacionalização (Furtado et alli, 2003).

Segundo a visão de Furtado et alli (2003), as licitações das plataformas P-51 e P-52 confirmam que há duas tendências claras a respeito das ações recentes da Petrobras: a intenção de desempacotar e nacionalizar a maior parte de seus empreendimentos. Tal postura da operadora brasileira vai de encontro às diretrizes apregoadas pelo governo Lula, mais precisamente, às diretrizes ecoadas pelo Ministério de Minas e Energia (MNE), quais sejam, da importância de se buscar instrumentos para aumentar o grau de nacionalização das compras da Petrobras de maneira competitiva e sustentável.

Deve-se destacar também que outro elemento que tem impelido a Petrobras a rever sua política de compras recentemente, é o fato de a ANP, preocupada com o destino da indústria de fornecedores locais, passar a incorporar nos critérios para seleção dos leilões de áreas de exploração e produção de petróleo e gás natural, índices de nacionalização. Contudo, salta à vista que a entrada do Lula no poder foi decisiva para a mudança na estratégia de compras da Petrobras. A criação do PROMINP torna evidente a intenção do novo governo em promover o desenvolvimento da indústria para-petroleira local, tendo como base o poder de compras da Petrobras. Estes dois mecanismos de política serão abordados a seguir. 


\section{Análise do Programa de Mobilização da Indústria de Petróleo e Gás Natural (PROMINP) ${ }^{12}$}

A nacionalização das compras da Petrobras foi uma promessa de campanha do então candidato à Presidência do Brasil, Luís Inácio Lula da Silva. Após sua eleição, houve uma determinação advinda do Ministério de Minas e Energia (MME) de se inserir nos processos licitatórios levados a cabo pela Petrobras, para aquisição de bens e serviços destinados aos seus projetos de E\&P, um mínimo de conteúdo local. Assim, quando ocorre a revisão das licitações da P51 e P-52 ${ }^{13}$, em janeiro de 2003, o MME em parceria com a Petrobras empreenderam um grande esforço para estabelecer qual deveria ser o conteúdo local mínimo razoável e factível.

A questão central para se decidir qual deveria ser este patamar era a de que seria necessário bom-senso para que não fosse estabelecido um patamar irrealista, uma vez que existem restrições de várias ordens quando se examina o estado de coisas da indústria para-petroleira local - como por exemplo, restrições no que diz respeito à escala, preço, logística e tecnologia. Portanto, percebeu-se que era algo premente resolver de que forma determinar uma meta de conteúdo local plausível, possível de ser alcançada, que não viesse a comprometer a qualidade, custo e prazo dos empreendimentos da Petrobras.

Para vencer essa barreira, os Departamentos de Engenharia e de E\&P da Petrobras decidiram começar a estruturar um programa de capacitação dos fornecedores locais. Foi mapeada, inicialmente, a capacidade atual desses fornecedores, tornando possível estipular um mínimo adequado às aquisições internas da Petrobras. Além disso, percebeu-se a necessidade de que fossem estabelecidas ações para capacitar os fornecedores locais, que lhes dessem condições para aumentar sua participação nos projetos de investimentos da Petrobras, de maneira competitiva e sustentável. Esse foi o nascedouro do Programa dentro da Petrobras, de acordo com as entrevistas realizadas junto a funcionários da Petrobras.

Logo, a partir das entrevistas realizadas, descobriu-se que o PROMINP começou a ser concebido dentro dos Departamentos de Engenharia e de E\&P da Petrobras, sendo, posteriormente, apresentado à Diretoria da companhia, a qual o aprovou. Além de tê-lo aprovado, a Diretoria da Petrobras resolveu, por enxergar naquele programa características de um programa de governo, apresentá-lo ao MME. O Ministério de Minas e Energia também deu seu aval e, mais do que isso,

\footnotetext{
${ }^{12}$ Foram realizadas entrevistas junto a alguns dos participantes do PROMINP para entender o escopo, a racionalidade e o funcionamento deste Programa. Portanto, neste artigo, utiliza-se de informações coletadas junto a membros da Petrobras, BNDES, ONIP e ABIMAQ.

${ }^{13}$ Em novembro de 2002, a direção da Petrobras decide mudar de dezembro para janeiro o prazo de entrega das propostas para a licitação das plataformas de produção de petróleo P-51 e P-52. O processo iniciado em setembro de 2002, era alvo de críticas do então candidato à presidência, Luiz Inácio Lula da Silva, o qual afirmava que a operadora nacional privilegiava empresas estrangeiras. Assim, coube à nova direção da Petrobras, indicada por Lula, decidir qual seria a proposta vencedora.
} 
percebendo que seu desenho tinha realmente características de um programa de governo, colocou-o em funcionamento e passou a encabeçá-lo.

Para decidir quais deveriam ser as medidas tomadas para alavancar a participação da indústria para-petroleira local nos projetos de investimento da Petrobras, foi realizado um workshop em Angra dos Reis, com cerca de 200 pessoas da indústria e do governo. Nesse worshop foram divididos grupos de trabalho pelos comitês setoriais e cada uma das entidades participantes teve a oportunidade de previamente preparar propostas preliminares de projetos, as quais foram debatidas no próprio workshop. Das conclusões da reunião em questão nasceu o Programa de Mobilização da Indústria Nacional de Petróleo e Gás Natural (PROMINP).

O PROMINP foi lançado pelo Presidente da República Luiz Inácio Lula da Silva, em 19/12/2003, no estaleiro da BrasFELS em Angra dos Reis (RJ). No evento que marcou seu lançamento, a Petrobras e o estaleiro BrasFELS assinaram os contratos para a construção da plataforma semi-submersível Petrobras 52 (P-52), destinada ao Campo de Roncador, na Bacia de Campos. Nessa mesma data, foi assinado pelo Presidente da República o Decreto No 4.925 que instituiu o PROMINP. O Artigo $1^{\circ}$ do Decreto $N^{\circ} 4.925$ estabelece que:

\footnotetext{
"Fica instituído o Programa de Mobilização da Indústria Nacional de Petróleo e Gás Natural - PROMINP, que visa fomentar a participação da indústria nacional de bens e serviços, de forma competitiva e sustentável, na implementação de projetos de petróleo e gás natural no Brasil e no exterior”.
}

A partir do discurso oficial, depreende-se que o PROMINP foi instituído pelo Governo Federal na perspectiva de fazer dos investimentos do setor de petróleo e gás natural, uma oportunidade de crescimento para a indústria nacional de bens e serviços, criando empregos e gerando riquezas para o Brasil. Além do MME e da Petrobras, participam do Programa o BNDES, o Instituto Brasileiro do Petróleo (IBP), a Organização Nacional da Indústria do Petróleo (ONIP), algumas associações de classe - como a Associação Brasileira da Indústria de Máquinas e Equipamentos (ABIMAQ), Associação Brasileira da Infra-estrutura e Indústrias de Base (ABDIB), Associação Brasileira dos Perfuradores de Petróleo (ABRAPET)-, o SEBRAE e federações de Indústria. O PROMINP é formado por três Comitês, a saber: Comitê Diretivo, Comitê Executivo e Comitê Setorial.

\subsection{A Carteira de Projetos do PROMINP}

O PROMINP, quando da sua criação, era composto de 47 projetos. Tal Programa pretende atuar em três grandes frentes, com vistas a fortalecer a indústria local de bens e serviços, a saber: Capacitação, Instrumentos de Política Industrial e Desempenho Empresarial. O "tema estratégico" 
Capacitação se desdobra em: Diagnóstico, Capacitação Tecnológica, Capacitação Industrial e Qualificação Profissional. No caso dos Instrumentos de Política Industrial, há a seguinte subdivisão: Financiamento, Regulação, Política Tributária e Fomento à Pequena e Média Empresa. E finalmente, o "tema estratégico" Desempenho Empresarial se subdivide em: Sustentabilidade, Competitividade e SMS (Meio Ambiente e Saúde). O quadro 1 apresenta os projetos iniciais do PROMINP e as frentes de atuação correspondentes.

Quadro 1: Distribuição dos Projetos do PROMINP de acordo com os Temas Estratégicos

\begin{tabular}{|c|c|}
\hline \multirow{4}{*}{$\begin{array}{l}\text { Capacitação } \\
\text { (Total: } 31 \text { projetos) }\end{array}$} & Diagnóstico -15 projetos \\
\hline & Capacitação Tecnológica - 5 projetos \\
\hline & Capacitação Industrial - 3 projetos \\
\hline & Qualificação Profissional - 8 projetos \\
\hline \multirow{4}{*}{$\begin{array}{l}\text { Instrumentos de política industrial } \\
\text { (Total: } 8 \text { projetos) }\end{array}$} & Financiamento -3 projetos \\
\hline & Regulação - 1 projeto \\
\hline & Política tributária -3 projetos \\
\hline & $\begin{array}{c}\text { Fomento à Pequena e Microempresa - } 1 \\
\text { projeto }\end{array}$ \\
\hline \multirow{3}{*}{$\begin{array}{l}\text { Desempenho empresarial } \\
\text { (Total: } 9 \text { projetos) }\end{array}$} & Sustentabilidade -6 projetos \\
\hline & Competitividade -2 projetos \\
\hline & SMS (Meio Ambiente e Saúde) - 1 projeto \\
\hline
\end{tabular}

Fonte: elaboração do autor.

A maior parte dos projetos apresenta características de projetos de diagnóstico. Por volta de um terço da carteira de projetos do PROMINP, ou seja, 15 projetos, são projetos de diagnóstico de lacunas. Em tais projetos é feito um levantamento da demanda da Petrobras e da capacidade atual de oferta dos fornecedores locais de bens e serviços, de itens específicos (sejam eles bens ou serviços). No início, se pensou em projetar a oferta, contudo tal exercício poderia gerar imprecisões, uma vez que quando se fala, por exemplo, em empresas de engenharia e construção e montagem, percebe-se que elas trabalham sob projetos, ou seja, sua capacidade produtiva varia em função do número de projetos em que elas se engajam. Na maior parte das vezes tais empresas não possuem uma equipe fixa muito grande. Portanto, salta à vista a dificuldade de uma empresa com essas características projetar sua capacidade de produção futura, notadamente quando se fala em um horizonte de tempo mais longo. 
Para resolver essa questão, decidiu-se que a melhor saída seria "congelar" a capacidade de oferta atual do parque supridor local de bens e serviços. Assim, para cada um dos itens que foram identificados como críticos, fossem eles de engenharia, construção e montagem, de materiais e equipamentos ou serviços foi realizado um mapeamento da demanda para os próximos anos e da oferta atual desses itens, de forma a identificar gargalos. Partindo destes gargalos, a intenção é agir antecipadamente, implementando ações estruturantes para minimizar, reduzir, ou até mesmo eliminá-los, de modo que a indústria de bens e serviços consiga atender competitivamente à demanda da Petrobras para os próximos anos.

Há projetos que também se caracterizam por serem projetos de análise. Contudo, não são projetos que visam analisar a capacidade de oferta dos fornecedores locais e contrastá-la com a demanda da Petrobras, mas sim, analisar possíveis medidas no campo da política tributária, de financiamento, de regulação e do fomento às pequenas e médias empresas que possam favorecer a atuação dos fornecedores locais.

E finalmente, existem alguns projetos nos quais, sabia-se de antemão da existência de determinados gargalos mesmo antes do advento do PROMINP. Então, pode-se dizer que estes projetos objetivam eliminar gargalos já conhecidos pela indústria de petróleo e gás natural. Portanto, no caso destes projetos, ações concretas já estão sendo implementadas, com vistas a melhorar as condições de fornecimento do parque supridor local, especialmente no que diz respeito aos problemas de qualificação profissional.

Depreende-se das entrevistas realizadas que existem três ciclos, três estágios de desenvolvimento, quando se examina os projetos do PROMINP, a saber: Ciclo 1, Ciclo 2 e Ciclo 3. Um projeto está no Ciclo 1 quando ainda há esforços no sentido de se levantar informações sobre determinado segmento, ou seja, quando ainda não foram sugeridas soluções para os gargalos do segmento em questão e, por conseguinte, nenhuma ação concreta foi tomada no sentido de sentido de sanar tais gargalos.

No Ciclo 2, os projetos se apresentam no estágio de estabelecimentos de propostas, após terem sido levantadas as deficiências da indústria para-petroleira local, a partir da seguinte confrontação: Demanda da Petrobras para os próximos anos versus Capacidade de Fornecimento dos Fornecedores Locais.

Finalmente, no caso dos projetos que se encontram no Ciclo 3, já há medidas sendo implementadas para solucionar as debilidades dos fornecedores de bens e serviços internos. Trata-se do estágio de desenvolvimento em que um gargalo já foi identificado, as possíveis soluções já foram discutidas internamente ao grupo de trabalho que faz parte do projeto, encaminhadas e aprovadas pelo Comitê Executivo e, portanto, já estão em fase de execução. 
Em seguida é apresentada uma analise acerca da participação da Petrobras no PROMINP. Tal analise demonstra-se deveras importante, uma vez que a operadora nacional, como será visto, é a maior compradora de bens e serviços da indústria de P\&GN do país.

\subsubsection{O PAPEL DA PETROBRAS DENTRO DO PROMINP}

A Petrobras é o maior demandante da indústria de petróleo e gás natural do país e busca, para os próximos anos, a auto-suficiência do Brasil em petróleo. A carteira de investimentos da Petrobras para o período 2004-2010 é de US\$ 53,6 bilhões, divididos da seguinte maneira: US\$ 32,1 bilhões para E\&P, US\$ 11,2 bilhões para downstream, US\$ 1,4 bilhão para áreas corporativas, US\$ 1,7 bilhão para distribuição, US\$ 6,1 bilhões para gás e energia e US\$ 1,1 para petroquímico. Desta carteira de investimentos, US\$ 46,1 bilhões serão investidos no Brasil e o restante (US\$ 7,5 bilhões) no exterior, o que representará um investimento anual médio de US\$ 6,6 bilhões no país e US\$ 1,1 bilhão no exterior.

Dos dados apresentados acerca da carteira de investimentos da Petrobras para os próximos anos, evidencia-se a magnitude do mercado representado pelas compras da Petrobras para os próximos anos e, por conseguinte, as oportunidades que tal mercado representa à indústria parapetroleira local, sobretudo a envergadura das aquisições que a estatal realizará para sua área de exploração e produção de petróleo e gás natural.

Posto isso, os projetos da Petrobras são os grandes impulsionadores do PROMINP. Disso decorre a denominação "Agente Balizador" do Programa, concedido à Petrobras. As entrevistas realizadas junto a funcionários da Petrobras que participam do PROMINP, dão conta que o interesse maior da Petrobras com o Programa é atender a demanda dos seus investimentos, mantendo as condições de competitividade e sustentabilidade, no que diz respeito a prazo, qualidade e custo. O objetivo da Petrobras com o Programa passa pelo fomento à indústria local, aumento do conteúdo local, geração de riquezas para o país e geração de empregos internamente. Contudo, desde que os critérios de qualidade, prazo e custo de suas obras sejam atendidos, uma vez que a Petrobras, embora seja estatal, é uma empresa que está inserida em um mercado competitivo, tendo, portanto, que manter seu padrão de competitividade.

Segundo os funcionários da Petrobras entrevistados, nas décadas de 1970 e 1980 o programa de compras da Petrobras se alicerçava na proteção do mercado interno. Era, portanto, um programa paternalista de compras governamentais, que serviu, em parte, para mascarar a fragilidade da indústria para-petroleira local. Essa estratégia de compras levada a cabo pela Petrobras decorreu, em boa medida, das pressões advindas do governo brasileiro para que as estatais substituíssem suas aquisições de bens e serviços importados, por aquisições de bens e serviços produzidos no Brasil. 
O paternalismo de outrora, ou seja, a aquisição de bens e serviços no mercado doméstico a qualquer preço, a qualquer custo e em qualquer prazo, deve transitar, segundo a visão da direção da Petrobras, para um modelo de compras que se baseie na competitividade da indústria para-petroleira local. Assim, percebe-se que o objetivo é fazer do PROMINP um modelo de política industrial, tecnológica e de geração de empregos, distinto do modelo da primeira fase da política de compras da Petrobras.

Conforme o que foi apurado nas entrevistas, o PROMINP busca criar um fórum de oportunidades para o parque supridor local a partir da carteira de investimentos da Petrobras - a agente balizadora do Programa - para os próximos anos, que leve em conta a sustentabilidade e a competitividade deste segmento industrial. De acordo com as entrevistas realizadas, busca-se com o PROMINP criar um novo modelo de política de compras dentro da Petrobras, diferente do modelo paternalista que vigorou na fase substitutiva de importações. Para alcançar este objetivo, a estrutura de governança criada para gerir o Programa abarcou não apenas membros do governo e da Petrobras, como também entidades da classe empresarial. Pretendeu-se com a incorporação de entidades da classe empresarial na estrutura de governança do PROMINP, aproximar o governo e a Petrobras da indústria para-petroleira local, tornando possível que tal indústria exponha suas debilidades e demandas.

As entrevistas realizadas junto a funcionários da Petrobras dão conta que a operadora nacional está empenhada em fazer do PROMINP um sucesso. Segundo os entrevistados, há a intenção por parte da operadora brasileira, que através deste Programa, ela se aproxime do parque supridor local e passe a trabalhar em conjunto com ele, para fomentar a competitividade e a sustentabilidade do fornecimento da indústria para-petroleira do país. Ainda assim, observou-se que o desnivelamento entre estes dois atores - Petrobras e fornecedores locais - poderá se configurar em um obstáculo ao sucesso do PROMINP.

\section{Conclusões}

O relativo sucesso da política de desenvolvimento da indústria para-petroleira ancorada na substituição de importações não foi suficiente para afastar tal indústria dos efeitos nocivos das reformas de cunho neoliberal implementadas pelo Estado brasileiro ao longo da década passada. Aqui, é oportuno observar as dificuldades que passam a enfrentar as empresas de engenharia e a indústria de bens de capital sob encomenda a partir dos anos 1990. Muitas dessas empresas faliram e outras foram adquiridas por empresas estrangeiras, tendo em vista que a Petrobras diminui consideravelmente suas aquisições locais. Portanto, ficou patente a idéia de que o estímulo à concorrência em qualquer indústria, não deve ser visto como um fim em si mesmo, notadamente quando se trata de um país periférico como é o caso do Brasil. 
Conforme apresentado, a política de compras da estatal brasileira começou a se alterar a partir do início da década atual. O modelo de compras da operadora brasileira para suas atividades offshore no período recente apresenta elementos que se afinam com a questão do desenvolvimento da indústria local. Tal postura da Petrobras vai ao encontro das novas diretrizes apregoadas pelo governo Lula, mais precisamente, às diretrizes emanadas da atual gestão do Ministério de Minas e Energia (MME), que destacam a importância da utilização de instrumentos que promovam um aumento na nacionalização das compras da operadora nacional.

Com vistas a analisar se ocorreram avanços significativos na política de compras da Petrobras no período atual, empreendeu-se uma análise do PROMINP, programa lançado pelo MME no ano de 2003. Tal Programa tem por objetivo fazer do programa de investimentos da Petrobras para os próximos anos uma oportunidade para a revitalização e o desenvolvimento da indústria para-petroleira local. O lançamento do PROMINP corrobora a intenção do governo atual em redirecionar as compras da Petrobras ao mercado doméstico.

Tendo em vista que o Programa ainda estava em seu primeiro ano quando da realização desta pesquisa, não há como afirmar que realmente ele logrará sucesso em substituir de maneira massiva e sustentável as importações realizadas pela Petrobras, sobretudo no que diz respeito aos seus investimentos para a construção de plataformas para operarem na bacia marítima brasileira.

Assim como, esta pesquisa não permite atestar que o PROMINP se tornará um mecanismo de estimulo à capacitação tecnológica e inovatividade dos fornecedores locais, fomentando a internacionalização dessas empresas.

Seria necessário um tempo maior para observar se as frentes de atuação do Programa, como capacitação tecnológica, financiamento, política tributária, capacitação profissional, sustentabilidade, entre outras, estarão bem articuladas para que promovam, de maneira exitosa, o desenvolvimento produtivo e tecnológico do parque supridor local. As entrevistas realizadas junto aos participantes do PROMINP, não permitiram que se tivesse uma visão clara de como funcionará o financiamento para a execução do Ciclo 3 dos projetos, por exemplo.

Logo, os projetos que visam substituir competitivamente as importações da Petrobras e gerar “equipamentos pioneiros” precisam chegar ao Ciclo 3, para que seja possível ter uma percepção mais nítida de como se comportará a política de compras da Petrobras, ou seja, se esses projetos realmente se configurarão em plataformas para o aprendizado e a capacitação tecnológica para inovar dos fornecedores locais. Contudo, depreende-se da pesquisa realizada que a maior parte dos projetos do PROMINP visa dar condições para que se passe a produzir no Brasil bens e serviços que existem em outras partes do mundo, sendo, por conseguinte, projetos de substituição de importações. 
Isso não significa dizer que tais projetos não envolverão desenvolvimento de capacitação tecnológica endógena. Nos projetos vinculados aos temas estratégicos "capacitação tecnológica" e “capacitação industrial” está colocada a importância da promoção da capacitação e do aprendizado tecnológico dos fornecedores locais, para a viabilização substituição competitiva e sustentável das importações da Petrobras. De acordo com as entrevistas realizadas, esses projetos demandarão esforço tecnológico por parte dos fornecedores locais, em cooperação com universidades, institutos públicos de pesquisa e a Petrobras.

Entretanto, o que já se pode dizer acerca do PROMINP é que ele é muito mais uma ferramenta para coordenar as ações dos atores direta e indiretamente interessados no desenvolvimento da indústria de petróleo e gás natural local (abarcando o Governo, a Petrobras e o parque supridor local). Logo, depreende-se que ele é um mecanismo para azeitar o Estado, melhorar a eficiência de mecanismos e políticas já existentes, do que propriamente uma inovação em termos de política de fomento à indústria. Além disso, como apurado junto a alguns participantes do PROMINP, há algumas falhas no sistema de financiamento brasileiro como a burocratização e a morosidade na avaliação de projetos, destacando-se o caso da FINEP, justamente a agência de fomento criada pelo governo brasileiro com a finalidade de financiar inovações tecnológicas no parque produtivo do país.

Conclui-se acerca pesquisa realizada que o ciclo de investimentos da Petrobras para os próximos anos é de grande monta e que representa uma janela de oportunidades aos fornecedores locais em termos de aprendizagem e capacitação tecnológica, uma vez que a operadora nacional demandará equipamentos que precisarão operar a 3.000 metros de profundidade que, portanto, não estão na "prateleira”. Contudo, há poucos indícios de que a Petrobras irá demandar de fornecedores locais o desenvolvimento desses equipamentos.

Logo, o que esta pesquisa permite afirmar é que a estratégia de compras da operadora nacional se afina com o modelo substitutivo de importações, não promovendo, por conseguinte, uma transição do modelo competitivo (neoliberal - década de 1990) para um modelo mais avançado. Concluindo, a política de compras levada a cabo pela Petrobras na atualidade não avança no sentido de estimular a capacitação e a aprendizagem tecnológica para inovar do fornecedor local e, concomitantemente, não se coloca como um trampolim para as exportações destas empresas.

\begin{abstract}
This article deals with the Petrobras's procurement policy for its offshore enterprises in the recent period, more specifically from the government Lula, and is tied with the master dissertation of the author. The current government created some mechanisms to stimulate the aproach of the Petrobras with the local petroleum related industry, which during almost one decade of validity of the neoliberal model, saw orphan of the local model of acquisition of great majority of the materials
\end{abstract}


and necessary equipment to the activity of the national operator, that is, of the import substitution model. The creation of the PROMINP is a clearly example of the government objective in modifying this situation. Our objective in this work is to analyze until which point the new Petrobras's procurement policy for its activities of exploration and can separate itself of the traditional model of import substitution, in order to foment the qualification and technological learning of the local suppliers. For in such a way a bibliographical revision supported in existing literature concerning the historical trajectory of Petrobras's procurement policy is made in as an item, detaching the technological question in its purchases. In a third item it is presented analysis of the PROMINP. This analysis supports on documents and interviews carried through next to participants of this Program. Finally, in the last item, one searchs to analyze, from the elements presented in the two itens previous, if the current Petrobras's model of purchases effectively creates a new opportunity of learning and technological qualification to the local petroleum related industry.

Key-words: procurement policy; technological learning; petroleum related industry; PROMINP.

\section{Referências}

ALONSO, P. S. R. Estratégias Corporativas Aplicadas ao Desenvolvimento do Mercado de Bens e Serviços: Uma Nova Abordagem para o Caso da Indústria de Gás Natural no Brasil. Tese (Doutorado em Engenharia) - Instituto Alberto Luiz Coimbra de Pós-Graduação. Rio de Janeiro: Universidade Federal do Rio de Janeiro, 2004.

ALMEIDA, E.L.F. Por uma Política Petroleira Sustentável. Boletim Infopetro Petróleo \& Gás. N.11, ano 4, 2003.

AGÊNCIA NACIONAL DO PETRÓLEO. Anuário Estatístico. Disponível em <http://www.anp.gov.br>. Acessado em: $15 / 01 / 2005$.

BONNELI, R. e VEIGA, P. M. A dinâmica das Políticas Setoriais no Brasil na década de 1990: Continuidade e Mudança. Revista Brasileira de Comércio Exterior, n. 75, 2003.

FURTADO, A. et alli. Assessment of direct and indirect effects of large technological programmes: Petrobras Deepwater Programme in Brazil. Research Evaluation, n.3, vol. 8, 1999.

cross ${ }^{\text {eef }}$

FURTADO, A. Mudança Institucional e Política Industrial no Setor Petróleo. Revista Com Ciência. Disponível em: http://www.comciencia.br/framebusca.htm, 2002.

FURTADO, A. et alli. Política de Compras da Indústria do Petróleo e Gás Natural e a capacitação dos Fornecedores no Brasil: o mercado de equipamentos para o desenvolvimento de campos marítimos. Projeto CTPETRO/ Tendência Tecnológicas, 2003.

FURTADO, A. Mudança Institucional e Inovação na Indústria Brasileira de Petróleo. In Pesquisa Industrial Trabalho e Tecnologia, Ed. Kon, A. e Oliveira, G., Fapesp, 2004.

MACEDO e SILVA, A. C. Petrobras: a consolidação do monopólio estatal e a empresa privada (1953-1964). Dissertação (Mestrado em Economia) - Instituto de Economia. Campinas: Universidade Estadual de Campinas, 1985.

MACHADO, G. Estimativa da Contribuição do Setor Petróleo ao Produto Interno Bruto do Brasil. Nota Técnica ANP, Rio de Janeiro, 2002. Disponível em: <http://www.anp.gov.br $>$. Aceso em: 23/02/2005.

MARTINS, F. C. O Fundo CTPetro e o setor produtivo: análise de política científica e tecnológica para o desenvolvimento do fornecedor local de equipamentos e serviços para o setor de petróleo e gás natural. Dissertação (Mestrado em Política Científica e Tecnológica) - Instituto de Geociências. Campinas: Universidade Estadual de Campinas, 2003. 
SOUZA, J. H. Os Núcleos de Articulação com a Indústria: um instrumento de política tecnológica para o setor de bens de capital. Dissertação (Mestrado em Política Científica e Tecnológica) - Instituto de Geociências. Campinas: Universidade Estadual de Campinas, 1997.

TAVARES, Maria da C. Da Substituição de Importações ao Capitalismo financeiro. 9. ed., Rio de Janeiro: Rumo, 1973.

ZAMITH, M. R. A Industria Para-Petroleira Nacional e o seu Papel na Competitividade do Diamante Negro Brasileiro. Dissertação (Doutorado em Energia) - Programa Interunidades de Pós-Graduação em Energia. São Paulo: Universidade de São Paulo, 1999.

Dados completos de todos os autores:

Nome completo: Cássio Garcia Ribeiro Soares da Silva

Filiação institucional: Unicamp

Departamento: Departamento de Política Científica e Tecnológica/IG

Função ou cargo ocupado: Doutorando

Endereço completo para correspondência (bairro, cidade, estado, país e CEP): Avenida 34, n. 884, Santana, Rio Claro - SP, CEP: 13504-110.

Telefones para contato: (19) 35325713

e-mail: cassio@ige.unicamp.br

\section{Nome completo: André Tosi Furtado}

Filiação institucional: Unicamp

Departamento: Departamento de Política Científica e Tecnológica/IG

Função ou cargo ocupado: Professor Titular

Endereço completo para correspondência (bairro, cidade, estado, país e CEP): R. João Pandiá Calógeras, 51, Unicamp - Campinas - SP. CEP: 13083-870

Telefones para contato: (19) 3521.4558

e-mail: furtado@ige.unicamp.br

Recebido para publicação em: 17/07/06

Aceito para publicação em: 18/09/06 